\title{
Characterization of Confectionery Spreadable Creams Based on Roasted Sunflower Kernels and Cocoa or Carob Powder
}

\author{
Emil RACOLȚA*, Sevastiţa MUSTE, Andruţa Elena MUREŞAN, Crina MUREŞAN, Monica BOTA, \\ Vlad MUREŞAN \\ ${ }^{1}$ Food Engineering Department, Faculty of Food Science and Technology, University of Agricultural Sciences and \\ Veterinary Medicine Cluj-Napoca - RO-400509 - Cluj-Napoca, Calea Floreşti, 64, Romania \\ *emil.racolta@usamvcluj.ro
}

Bulletin UASVM Food Science and Technology 71(1) / 2014

ISSN-L 2344-2344; Print ISSN 2344-2344; Electronic ISSN 2344-5300

\begin{abstract}
Spreadable creams are solid-oil suspensions, a mix of fats represents the oil phase, the dispersed phase consisting usually of sugar, cocoa powder, milled and roasted nuts, dried milk and whey. For improving the viscosity of the final product emulsifiers are used, most common being lecithin and mono and diglycerides.

The present paper refers to a spreadable confectionery product group, creamy, proper to be eaten as it is, as well as spread on a bread slice or as a filling for cookies or chocolate cream.

According to this work, the following ingredients were used: roasted sunflower kernels, sugar, palm oil, cocoa or carob powder and lecithin. The obtained product can be consumed also by persons who suffer from allergies, due the fact that sunflower seeds were replacing the peanuts or almond, the ingredients known as allergens and which are usually used in the technological process of obtaining these creams.

The purpose of this study was to characterize the obtaining confectionery spreadable creams based on sunflower kernels, cocoa or carob powder. It was determined the chemical composition of the prototypes obtained, a spreadable cream having no cocoa or carob, one with cocoa and one with carob powder. The antioxidant capacity and total phenolic content of the obtained samples were also assessed.
\end{abstract}

Keywords: spreadable cream, sunflower-seed, carob, antioxidant capacity, phenolic compounds.

\section{INTRODUCTION}

Although nearly any food is capable of causing an allergic reaction, peanut allergy is one of the most common food allergies. Food allergy is affecting up to 15 million people in the United States, including 1 in 13 children.

Allergy to peanuts appears to be on the rise in children.According to astudy funded by Food Allergy Research \& Education, the number of children in the US with peanut allergy tripled between 1997 and 2008. Studies in the United Kingdom and Canada also showed a high prevalence of peanut allergy in schoolchildren (www.foodallergy.org).
Chocolate products are the most important confectionery that is popular especially for children and as a source of energy in addition to its high nutritional value. In chocolate industry, many of ingredients such as cocoa, sugar, cocoa butter, play an important role in product quality.

So, it was created a product that is trying to meet market requirements, in terms of both people with allergies to peanuts and persons allergic to cocoa, the product being free of allergens, but also for those who love chocolate.

Research underway in the palm oil industry has revealed a range of bioactives than can be 
used as functional components for food product that enhance health. Carotene is one of the most important functional components in palm oil (Tan et al., 2007).

The oil palm fruit was identified as an excellent source of two major phytochemicals, namely vitamin E (tocopherols and tocotrienols) and carotenoids, both of which are fat-soluble. Oil palm vitamin $\mathrm{E}$ has been reported to act as a potent biological antioxidant, protecting against oxidative stress and the atherosclerotic process (Sundram et al., 2003; Mukherjee and Mitra, 2009). Recently, oil palm fruits were also identified as a rich source of phenolic compounds (Sambanthamurthi et al., 2011).

Theobroma cacao L. the source of chocolate, is a species native to the rainforests of Central and South America (Bailey et al., 2009).

Cocoa beans, seeds of the tree Theobroma cacao L., are the primary raw material used in the manufacture of final products intended directly for consumption such as cocoa powder, chocolate bar and other cocoa derivative products which are highly valued by consumers around the world (Belscak et al., 2009).

Cocoa-products are an important source of phenolic compounds such as proanthocyanidins (PAC) and monomeric flavan-3-ols. The consumption of cocoa with high levels of procyanidins and epicatechins, despite the high contents of saturated fatty acids, has been associated with benefits to human health including increased plasma antioxidant capacity and lower lipid peroxidation, a mechanism of protection in heart disease (Katz et al. 2011).

Carob pods are characterized by high sugar content (more than 50\%), mainly sucrose (32$38 \%)$, glucose $(5-6 \%)$, fructose $(5-7 \%)$ and maltose (Binder et al., 1959; MacLeod and Forcen, 1992). Carob is a natural sweetener with a flavor and appearance similar to cacao. Carob is often used as a chocolate or cocoa substitute (Brand, 1984; Nyerges, 1978). Such usage is attributed to the fact that carob has the advantage of being caffeine and theobromine-free whereas chocolate and cocoa contain relatively high amounts of these two antinutrients (Craig and Nguyen, 1984).

Carob contains about 18\% cellulose and hemicellulose. The mineral composition (in mg per $100 \mathrm{~g}$ of pulp) is: $\mathrm{K}=1100, \mathrm{Ca}=307, \mathrm{Mg}=42$, $\mathrm{Na}=13, \mathrm{Cu}=0.23, \mathrm{Fe}=104, \mathrm{Mn}=0.4, \mathrm{Zn}=0.59$ (www. sigmaaldrich.com).
Sunflower seeds may be consumed directly as seeds, roasted with or without the hull, using the varieties with the lower content in the oil (approximately 30\%) thicker in shell, a poor adhesion to its kernel. Components that are involved in the composition of chemical sunflower (fat, protein, cellulose, ash) are depending on variety and growing conditions.

Sunflower seeds contain around $20 \%$ protein, a high level of potassium (710 mg/100g) and magnesium (390mg/ 100g) and particularly is rich in polyunsaturated fatty acids (approximately $31 \%$, as compared with other seeds and oleaginous fruit: soybeans (3.5\%), groundnut (13.1\%), linseed (22.4\%), sesame seed (25.5\%) and sunflower seeds (28.2\%) (Skrbic and Filipcev, 2008).

Sunflower seeds contain a significant quantity of vitamin E - $37.8 \mathrm{mg} / 100 \mathrm{~g}$, unlike linseeds, sesame and soya bean, which contain less than $3 \mathrm{mg} / 100 \mathrm{~g}$, while peanut is estimated to contain $10.1 \mathrm{mg} / 100 \mathrm{~g}$ of vitamin E (Skrbic and Filipcev, 2008).

\section{MATERIALS AND METHODS}

Roasted sunflower kernel production

Roasted sunflower seeds were obtained from a mix of industrial sunflower seeds, from the harvest of 2012. After quantitative and qualitative reception of sunflower seeds, before being passed into the dehulling machine, the final cleaning of the seeds was achieved by a vibro-vacuum cleaner.

Products resulting from the dehulling machine were separated in a plansifter resulting the sunflower kernels, unhulled and partially dehulled seeds, hulls and kernel dust. Unhulled and partially dehulled seeds were resent to the dehulling machine, while the hulls and kernel dust were recovered as by-products.

The roasted sunflower kernel was obtained in a continuous equipment at $120^{\circ} \mathrm{C}$ and then cooled under the current of air $\left(40-45^{\circ} \mathrm{C}\right)$.

Carob-Sunflower spreadable cream prototypes production

Prototypes (Tab. 1) were obtained in batches of four kilograms on the Pilot plant of the Department of Food Engineering, Faculty of Food Science and Technology, USAMV Cluj-Napoca. The roasted sunflower kernel was grinded at pilot plant scale, using a ball mill model WAFA 20, Mazzetti Renato, Italy. Working time for obtaining the spreadable creams samples was two hours, the rotor speed being kept constant. 
General chemical composition

Protein, fat, ash and moisture content of different samples was determined according to AOAC (2002) procedures.

The protein was determinated by the Kjeldahl method and shall consist of the total nitrogen determination which, multiplied with the coefficient of the transformation of nitrogen in protein, give the quantity of protein.

Fat was determinated by extraction with organic solvents in the Soxhlet apparatus. Ash was determinated by ashing at $550^{\circ} \mathrm{C}-600^{\circ} \mathrm{C}$ until white ash.

Moisture was determinated by drying a quantity of the sample at $103 \pm 2^{\circ} \mathrm{C}$ until a constant weight (Muste and Mureșan, 2011).

\section{Total polyphenol content}

\section{Extraction of samples}

In order to obtain extracts for total polyphenols determination, $\sim 1 \mathrm{~g}$ of the sample from each spread cream prototype was extracted in a mortar, with acidified methanol (MeOH: $\mathrm{HCl} 0.01$ $\%)$. The extract was separated and re-extracted up to become colorless. The filtrates obtained were combined in a total extract and solvent evaporated $\left(35^{\circ} \mathrm{C}\right)$. The dry residue was re-dissolved in a specific quantity of methanol according to requirements (Bunea et al., 2011).

\section{Determination of the total polyphenols}

Stock solution of sample extracts ( $25 \mu \mathrm{l}$ each) were dissolved in methanol and further dilution were performed to obtain readings within the standard curve made with gallic acid (Fig. 1) $\left(\mathrm{R}^{2}=0.999\right)$. The extracts were oxidized by the FolinCiocâlteu reagent $(120 \mu \mathrm{l})$ and the neutralization was made with $\mathrm{Na}_{2} \mathrm{CO}_{3}(340 \mu \mathrm{l})$, after 5 minutes. The absorbance was measured at $750 \mathrm{~nm}$ after 90 minutes, in the dark, at room temperature. The results were expressed as milligram of gallic acid per 100 grams.

Table 1. The protocol used to obtain spreadable creams based on roasted sunflower kernel and carob or cocoa powder

\begin{tabular}{ccccccc}
\hline Samples & $\begin{array}{c}\text { Sunflower } \\
\mathbf{\%}\end{array}$ & $\begin{array}{c}\text { Carob } \\
\mathbf{\%}\end{array}$ & $\begin{array}{c}\text { Cocoa } \\
\mathbf{\%}\end{array}$ & $\begin{array}{c}\text { Sugar } \\
\mathbf{\%}\end{array}$ & $\begin{array}{c}\text { Palm oil } \\
\mathbf{\%}\end{array}$ & $\begin{array}{c}\text { Lecithin } \\
\mathbf{\%}\end{array}$ \\
\hline Control sample (1) & 40.5 & - & - & 49 & 10 & 0.5 \\
\hline Carob prototype (2) & 40.5 & 8 & - & 41 & 10 & 0.5 \\
\hline Cocoa prototype (3) & 40.5 & - & 8 & 41 & 10 & 0.5 \\
\hline
\end{tabular}

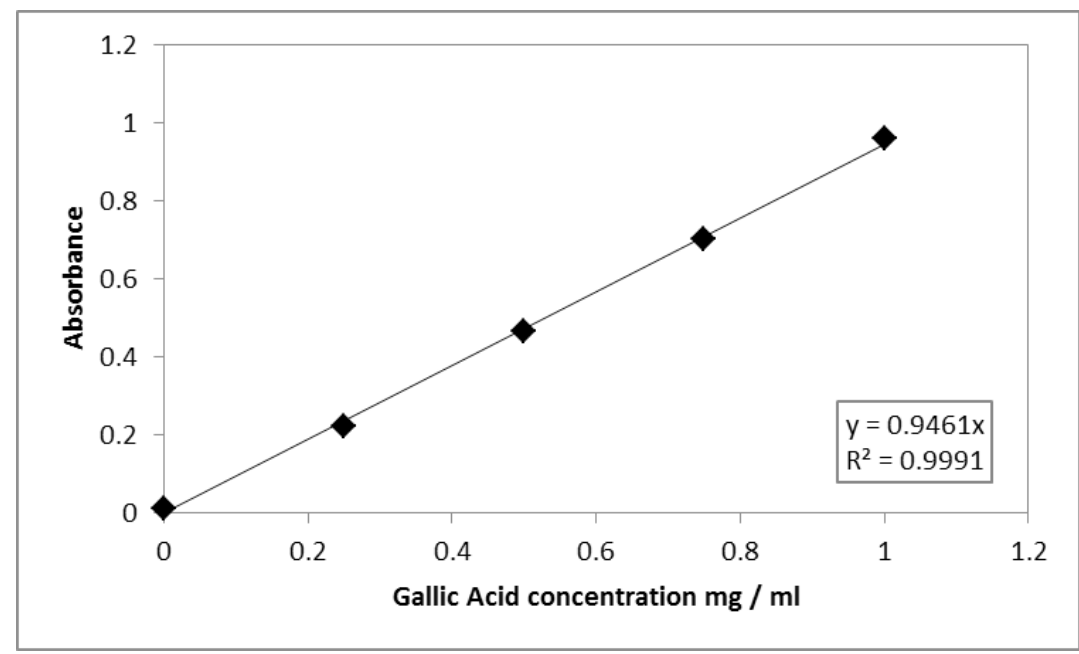

Fig. 1. Standard curve calibration for Gallic acid 


\section{Antioxidant capacity determination}

The antioxidant capacity was determinated through the evaluation of free radical-scavenging effect on 1,1-diphenyl-2-picrylhydrazyl (DPPH) radical.

This determination was based on the proposed method of Odriozola-Serrano et al. (2008). $10 \mu \mathrm{l}$ of methanolic sample extract was mixed with 3.9 $\mathrm{ml}$ DPPH $(0.025 \mathrm{~g} / \mathrm{l})$ and $90 \mu \mathrm{l}$ of distilled water. The mixture has been stirred properly and kept in the dark for $30 \mathrm{~min}$. The absorbance of samples was measured at $515 \mathrm{~nm}$ (UV-VIS 1700 Shimazdu) against a blank consisting of methanol. The results were expressed as percentage decrease with respect to the absorption value of a reference DPPH solution.

\section{RESULTS AND DISCUSSIONS}

Protein content of spreadable creams

Protein content (Fig. 2) of the cocoa prototype $(12.48 \%)$ has been greater than for other prototypes, the one based on sunflower and carob $(11.41 \%)$ and the control one $(10.56 \%)$. This can be explained by the fact that sunflower kernel has a protein content of $20-25 \%$ and determines roughly the protein content of the creams, while the addition of carob or cocoa causes an increase of the protein content.

\section{Fat content of spreadable creams}

The control sample had the highest content of fat, registering $33.98 \%$ (Fig. 3). However, the other two samples, carob and cocoa prototypes

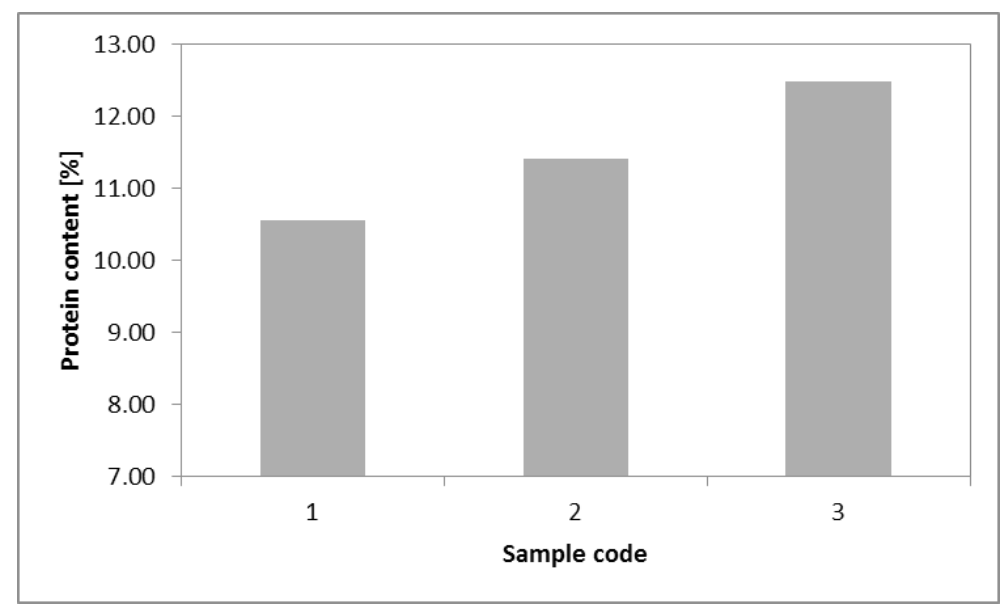

Fig. 2. The protein content of confectionery spreadable creams prototypes (1 - control; 2 - carob prototype; 3 - cocoa prototype)

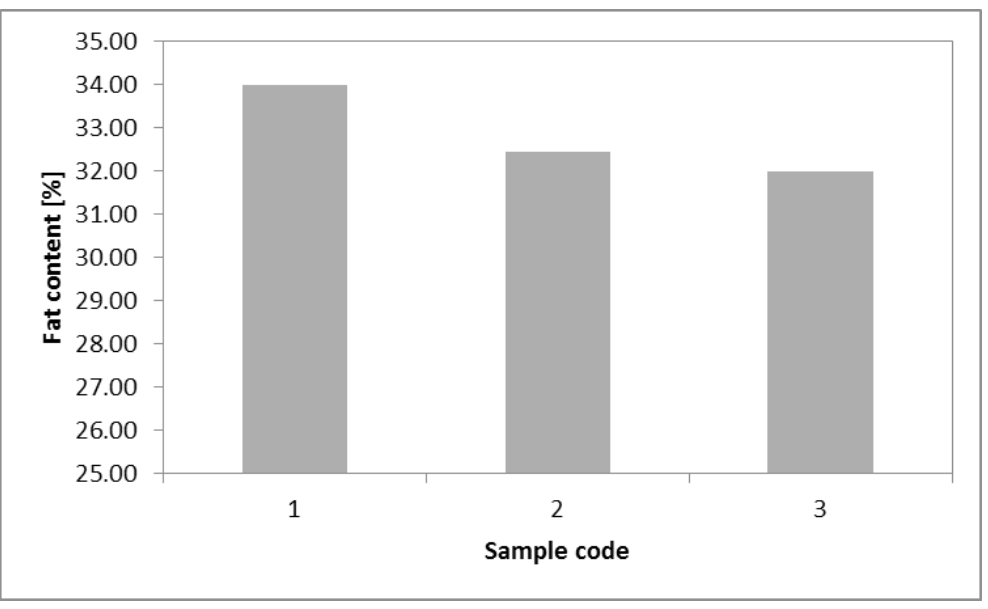

Fig. 3. The fat content of confectionery spreadable creams prototypes (1 - control; 2 - carob prototype; 3 - cocoa prototype) 
had also similar values $(32.42 \%$ and $31.98 \%)$. The prototypes analyzed in current work show values of fat content characteristics for similar confectionery products (e.g., chocolate fat content is between 28.5 and $35 \%$ ).

Ash and moisture content of spreadable creams

The ash content of the spreadable creams based on roasted sunflower kernel and carob or cocoa powder was between 1.38 and 2\% (Fig. 4). It can be seen a trend of increasing the ash content as the carob or cocoa powder was added.

Regarding the moisture content of analyzed spreadable creams, there were registered values of $0.28 \%$ for control, $0.69 \%$ for carob prototype and $0.41 \%$ for cocoa prototype, showing thus a high stability with minimum risk of microbiological growth.

Total polyphenol content and antioxidant capacity of spreadable creams

The results obtained for total polyphenol content and antioxidant capacity of spreadable creams based on roasted sunflower seed and carob or cocoa are presented in Table 2.

The cocoa prototype had registered the highest content of polyphenols as well as the highest value for antioxidant capacity. However, the carob prototype performed well, as it registered a close polyphenol content and antioxidant capacity to cocoa prototype. As expected, the control sample had the smallest values of both total polyphenol content and antioxidant capacity.

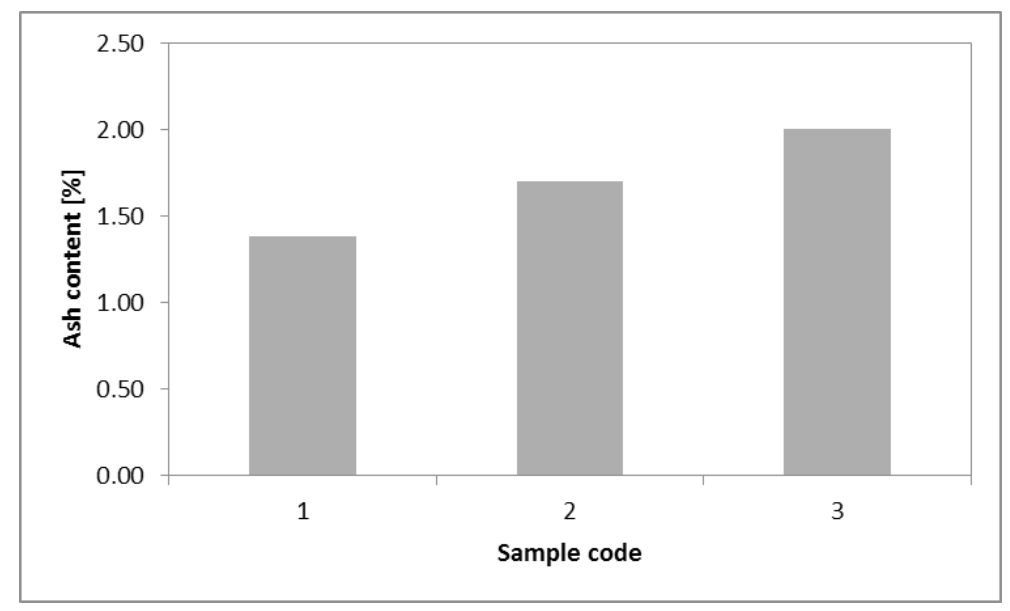

Fig. 4. The ash content of confectionery spreadable creams prototypes (1 - control; 2 - carob prototype; 3 - cocoa prototype)

Table 2 . The total polyphenol content and antioxidant capacity of spreadable cream

\begin{tabular}{lcc}
\hline \multicolumn{1}{c}{ Sample } & $\begin{array}{c}\text { Total polyphenol content } \\
{[\mathrm{mg} \mathrm{GAE} / \mathrm{100g}]}\end{array}$ & $\begin{array}{c}\text { Antioxidant capacity } \\
{[\%]}\end{array}$ \\
\hline Control sample (1) & 749.80 & 44.74 \\
\hline Carob prototype (2) & 844 & 52.20 \\
\hline Cocoa prototype (3) & 929 & 55.55 \\
\hline
\end{tabular}




\section{CONCLUSION}

This is a first study that focuses on the chemical characterization of the spreadable creams obtained from roasted sunflower kernels and carob or cocoa powder. The three analyzed samples showed values between $10.56-12.48 \%$ for protein, $31.98-33.98 \%$ for fat, $1.38-2 \%$ for ash and $0.28-0.69 \%$ for moisture. The results of the study showed that cocoa prototype contains high level of antioxidants and polyphenols, while the prototype with carob contains medium level of antioxidants and polyphenols.

\section{REFERENCES}

1. Belscak, A. et al. (2009). Comparative study of commercially available cocoa products in terms of their bioactive composition. Food research International 42:707-716.

2. Binder, R. J. et al. Brekke (1959). Carob varieties and composition. Food Technology 13: 213-215.

3. Brand, E. (1984). Carob. Nutrition and Food Science, 91: 22-24.

4. Bailey, B. A. et al. (2009). Trichoderma species form endophytic associations within Theobroma cacao trichomes. Mycological research, 113:1365-1376.

5. Bunea, A. et al. (2011). Comparative Polyphenolic Content and Antioxidant Activities of Some Wild and Cultivated Blueberries from Romania, Not Bot Horti Agrobo, 39:7076.

6. Craig, W. J. and Nguyen, T.T. (1984). Caffeine and theobromine levels in cocoa and carob products. Journal of Food Science, 49:302-306.
7. Katz, D.L. et al. (2011). Cocoa and chocolate in human health and disease. Antioxid Redox Signal, 15:2779-811.

8. MacLeod, G. and Forcen, M. (1992). Analysis of volatile components derived from the carob bean Ceratonia Siliqua. The International Journal of Plant Biochemistry, 31:3113-3119.

9. Muresan, C. and Muste, S. (2011). Cotrolul calității materiilor prime de origine vegetală. Editura AcademicPres, Cluj- Napoca.

10. Nyerges, C. (1978). The chocolate that is good for you. Organic Gardening, 12:122-126.

11. Sambanthamurthi, R. et al. (2011). Oil palm vegetation liquor: A new source of phenolic bioactives. British Journal of Nutrition, 106: 1655-1663.

12. Mukherjee, S. and Mitra, A. (2009). Health effects of palm oil. Journal of human Ecology, 26:197-203.

13. Škrbić , B. and Filipčev, B.(2008). Nutritional and sensory evaluation of wheat breads supplemented with oleic-rich sunflower seed. Food Chemistry, 108:119-129.

14. Sundram, K. R. et al. (2003). Palm fruit chemistry and nutrition. Asia Pac. J. Clin. Nutr. 12:355-362.

15. Tan, Y. A. et al. (2007). Valorisation of palm by-products as functional components. European Journal of Lipid Science and Technology, 109:380-393.

16. ***http://www.foodallergy.org/allergens/peanut-allergy (accessed on 15.04.2014).

17. ${ }^{* * *}$ http://www.sigmaaldrich.com/life-science/nutritionresearch/learning-center/plant-profiler/ceratoniasiliqua.html (accessed on 15.04.2014).***http://www. sigmaaldrich.com/life-science/nutrition-research/ learning-center/plant-profiler/ceratonia-siliqua.html (accessed on 15.04.2014). 